\title{
The Grammatical Accuracy, Cohesion and Coherence of Thai Students' English Writing at Darawithaya School, Narathiwat - Thailand
}

\author{
Ruqoyyah Amilia Andania \\ Email: andaniaeunoia@gmail.com \\ International Office \\ Universitas Islam Negeri Sunan Ampel \\ Surabaya, Indonesia.
}

\begin{abstract}
Writing has been recognized as an important skill to be mastered by all students both English as Foreign Language (EFL) and English as Second Language (ESL) students since many universities around the world offer writing courses. Hence, this study attempts to analyze the grammatical accuracy, cohesion and coherence of Thai Students' English Writing at Darawithaya School. This study is designed to investigate (1) the grammatical accuracy on Students' Writing, and (2) the cohesion and coherence on Students' Writing. The participant of the study consists of 14 Second Grade Students of Senior High School who enroll Academic Education at Darawithaya School, Narathiwat - Thailand. Since this study is descriptive qualitative approach, the data is documentation from students' writing work. Some guidelines and rubric are used in this research for analyzing. The findings reveal that there are 73 errors are found on 14 students' composition in this study. They occur on singular/plural followed by subject omission, the use of article, pronoun, preposition, verb omission, $\mathrm{S}-\mathrm{V}$ agreement, word formation, tense, and extraneous subject. Consequently, those errors make students' grammatical accuracy value varied from one student to other students.
\end{abstract}

Key Words: Writing, Grammar Accuracy, Cohesion and Coherence

\section{INTRODUCTION}

Writing is an essential part of engaging in professional, social, community, and civic activities for everyone, because writing is a valuable tool for communication, learning, and self-expression (Somchai and Siriluck: 2012). Writing English is not a simple task for all learners, mainly to non-native learners. Learners who learn English as a second language (ESL) or English as a foreign language (EFL) have 
to spend a lot of time and struggle to be intent in obtaining the language and learning on how to write well.

Santos explains that there are three reasons of making writing increasingly essential, which are; first, more international linguists are promoting writing as their field of concentration, second, more articles and journals are available in English for this age, and last, more international students are pursuing their degrees in English speaking countries, like Australia, England, America, Filipina Canada, and others (Somchai and Siriluck: 2012). Considering those three main reasons, becoming something a must for all ESL/EFL learners to have good knowledge in writing English to enlarge global knowledge and global community to then be able to compete in this era. English becomes a compulsory subject for Thai students from primary to tertiary levels, but commonly they think more in Thai than in English. In this case, English is not used as the instructional medium or communication language in other subjects in Thai educational institutions, as it is in Singapore, Malaysia, and the Philippines. On the other hand, the importance of writing in Thailand has been recognized since many universities provide writing courses as both elective and compulsory subjects for students to register.

Most students of Darawithaya School, Narathiwat-Thailand disposed mastering their knowledge in religion subjects (Arab). Meanwhile, English becomes a foreign language which is difficult to be mastered, therefore English is rarely used in their daily conversation, both spoken and written. They use Thai and Melayu Pattani for their communication language. This reality makes them get difficulty in building their competence in English.

This study is focused only on the grammatical accuracy, however there are various other types of accuracy in writing, as lexical and semantic which both are similarly become a significant case in presenting valuable information and comprehensions dealing with the learner's knowledge on how a second language or foreign language is learned and received by students. This focus is based on consideration that one of the most frequent errors in Thai students' English writing lies on the grammar that has been found to be a major source of 
writing errors (Pairote: 2008). Celce-Murcia emphasized the importance of a reasonable degree of grammatical accuracy in academic writing. She stated that high frequency of grammatical errors in nonnative speaker's academic writing (an average of 7.2 errors per 100 words) most probably makes their writings unacceptable to the University faculties (Sasan: 2012). In the other sources, she also highlighted that the writing process is necessary for being a successful writer in a second or foreign language to express the ideas with reasonable coherence and accuracy. As stated by Norrish that it is important to be able to write sentences that are acceptable and grammatically correct (Tiptida: 2008). It means that writers should write writing which is acceptable for the readers in giving understanding meaning in each sentence. As stated by Jeremy Harmer on his book, "for writing to be truly accessible, however, it also needs to be both cohesive and coherence" (2004). This statement means that a writing will be truly acceptable for readers if it has both cohesion and coherence aspect on the text itself. Therefore, other than grammatical accuracy aspect this study also concerns on those two aspects in analyzing students' writing.

This research is interested in examining the grammatical accuracy, coherence and cohesion which participants perform in their writing. Therefore, the research questions will be (1) how is the grammatical accuracy of Thai Students' English Writing at Darawithaya School? and (2) how are the cohesion and coherence of Thai Students' English Writing at Darawithaya School?

\section{RESEARCH DESIGN}

The goal of this study is to examine and then describe the profile of grammatical accuracy, cohesion and coherence on English writings which are produced by Thai students at Darawithaya School. Considering the goal, this study is included as qualitative design using descriptive approach, since it tries to describe a phenomenon of language behavior. As stated that one of the characteristics of qualitative study is the natural setting since its goal is to describe social phenomenon as it occurs naturally without manipulation (Donal: 
2009). It only focuses on understanding the context and attempts to explain the intentionality of behaviors (2009). By those functions of qualitative research, it is believed to be an appropriate method in this current study, since it tries to give a description of phenomenon in language behavior naturally without manipulation. Descriptive approach is used in this research since it is designed primarily to describe what is going on or what exists (William: 2001). Whitney states that descriptive qualitative is a data collection which interprets the fact truly (Whitney: 1960). This way agrees with the requirements in this recent study. Documents os students' writing works are the data of this recent study. Document is believed as a valuable source of information in qualitative research (Creswell: 2012).

The participants of this research are students of Mathyum 5 grade in academic school of Darawithaya School, Narathiwat, Thailand. This grade is equal with second grade students of Senior High School. At that school, Mathyum 5 is devided into $5 / 1$ and 5/2. Then, 5/2 class is selected in this study because the researcher was assigned in that class since being a teacher at Darawithaya school.

Since English writing is crucial in this modern age for both ESL and EFL students, this study aims to examine Thai students' writing work based on the grammatical accuracy and the cohesion and coherence. The scope of this study is focused only on the grammar. Besides that, as consideration of focusing on grammar accuracy, it lies on the fact that ESL/EFL learners have dedicated various types of grammatical errors in their written products. A number of studies in the field of error analysis have investigated types of errors committed by learners from a variety of first language backgrounds such as Spanish, German, Swedish, Arabic, Chinese, and Japanese in the acquisition of English as a second language or English as a foreign language. (Ayuwaratana: 2002). However, there is little information available concerning errors made by Thai EFL learners. As stated in the previous discussion, the assessment of ESL/EFL writing not only concerns in grammatical accuracy but also in discourse organization. So, it is important in examining those two aspects of cohesion and coherence to ensure that 
the learners demonstrate successful performance on grammatical accuracy and both cohesion and coherence.

Then, this study is also narrowed into a group of Thai EFL students who are at second grade of senior high school of Islamic Foundation. Besides that, the samples of this study are taken from the students' writing materials which have been given in their class. So, the result of this study may be inapplicable for other level and other writing types.

As the data in this study is the writing samples produced by the participants of this study, the first step of this analysis data process is organizing all the writing samples. The next step is analyzing all the writing samples to see the grammatical accuracy and the cohesion and coherence which are performed on participants' writing. After analyzing those two aspects in the writing samples, the last step is describing and interpreting what have been known dealing with the grammatical accuracy and both cohesion and coherence on students' writing. Then, conclusion will be provided.

\section{FINDINGS}

\section{Grammatical Accuracy}

Answering the first research question including the grammatical accuracy on students' writing, some certain grammar categories are decided to be analyzed. Those grammar categories are based on Standard English grammatical rule which is provided in any grammar book. Specifically, the guideline of grammar categories suggested by Polio is used in this research, as stated and showed in the previous chapter (Polio:1997). After analyzing and categorizing, then the result is described and explained in detail of each error type by enclosing the examples found on each composition. In this analysis, some grammar books are used as the sources to support the validity of this result.

Student 1 (ST1) The result of the analysis shows that there are some errors presented on the composition especially in the use of singular/plural noun. The errors of this category are found in some sentences. For example: "My mother has seven brother", "and my mother has two sister", "and four brother", and "my sister are single. My first sister is a 
student. She is tall, friendly, good-looking. She is 17 years old. Second sister is a student. She is beautiful, tall, and kind”. Then, student 1 also presents one error of using pronoun. It occurs on the sentence "My father is a teacher at Bon Sipo School. She is good-looking, kind, fat...." In the use of pronoun "she" here refers to a man, my father. In this case, my father is the antecedent of that sentence.

Student 2 (ST2) Student 2 only makes two errors in the use of singular/plural category, one article, and one $\mathrm{S}-\mathrm{V}$ agreement. Whereas, for the other grammar categories are presented in free from error. Here are the errors that student 1 makes in the use of singular/plural. For example: “.......... my mother has four sisters and two brother", and "My sister and single. My first sister is a student........ My second sister.........." Then, the error also occurs on the use of article. It happens in sentence "my fourth sister is student". Besides those two categories, student 2 also makes an error in the use of $\mathrm{S}-\mathrm{V}$ agreement. It happens in the sentence that has been mentioned above, that is "My sister and single. My first sister is a student......... My second sister............ Student 3 (ST3) There are two errors of all categories that student 3 makes. They are only in the use of article. Each of them occur on the sentence "He is $\underline{a}$ handsome, brave, clever, and kind" and "she is a fat, beautiful, and kind".

Student 4 (ST4) The result of the analysis indicates that the grammatical accuracy of student 4 consists of ten of twelve categories are presented with no errors. Only the use of singular/plural and word form categories which are presented with some errors. The first error is in the use of singular/plural noun. The errors of this category are found in some sentences. They are "........ and my mother has one sisters and one brother", "My sister are married, and they have many children. My first sister is...... My second sister is.... My third sister..... My fourth and fifth sisters......", and "My fourth and fifth sisters do not have any children". Student 4 also presents two errors in using word formation. It occurs on the sentence, “... and she has two___, and "...... and she has redhair, and she is sister". Student 5 (ST5). The analysis of grammatical accuracy shows that there are some errors are presented on the composition especially in the use of subject omission. The errors of 
this category are found in some sentences. For example: "is five years old" and "is good-looking thin and kind". On the other hand, there are some sentences which are lack of complete subject. This error occurs on the sentences"She is good-looking, kind, and clever name is Abidah", "name is Amati", "first old brother name is Arfan", and "second old brother name is Anah". Extraneous subject is also found in error appearance. The sentence "Sister she is a beautiful, clever........... ", the subject is provided in double, "sister" and "she". The other error category that is found is the use of pronoun. "I love my mother she is a beautiful patient............. He name is Aruni" is the sentence evidences that the use of pronoun is inappropriate of this sentence. The use of pronoun "he" did not represent the previous subject that student 5 intends to be explained. For the last error category of grammar is found on the use of article. "Sister she is a beautiful, clever............".

Student 6 (ST6) There is only little error presented on the composition, they are two errors in the use of singular/plural noun and one is in the use of article. The errors of these categories are found in some sentences. For example: ".......... she has three children, one boy, and two girl”, and "..... she has five children, four boy and one girl.". The other error occurs on the use of article. "My father is a Engineer" is the sentence that provides the error of article by using - a. Student $\mathbf{7}$ (ST7) There are only two error sentences found. "...... my mother has three sisters and one brothers", and "......... and he has two son”. Student 8 (ST8) The analysis shows that there are only three errors appear on that composition. They are two errors of singular/plural use, and one error of S-V agreement. Those three errors occur on the sentences below: "..........brothers and one sisters", "My brother are single", and ".... and my mother five brothers". Student 9 (ST9) There are some errors that are presented on the composition of student 9 especially in the use of singular/plural noun. They are found in sentence "My father has three sister", "he is eight year old", "he is three year old" and "my brother are single" On the other hand, the error is also found in the use of S-V agreement. It occurs on the sentence "My family live in balo" and "he has clever, handsome....". The other error happens in the category of subject omission and verb omission. These two errors are found in one sentence; "My fourth name barakat". Seen from the context of the 
paragraph, student 9 intends to explain her brother because the previous sentence presents the information of her third brother. Not only the use of noun which is neglected in that sentence but also the auxiliary. In occurs on the sentence, "My fourth brother's name is barakat". Student 10 (ST10) Two errors are in the use of singular/plural, and one is in the subject omission category. Those errors are presented in the sentence "two young sister", "One young brothers" and “...is 45 years old". Whereas the other categories of Standard grammar rule are presented with no error. Student 11 (ST11) This composition shows that the errors happen in five sentences; "he name is Rohimah", "his name ma'sadee", " .... is seven years old”, "sisther she is a good-looking, beautiful.....", and "....... and red hairs anahan she is 5 years old".

Student 12 (ST12) There are some grammar rules that are presented inaccurately. They occur on the use of appropriate article, preposition, and subject. For examples: "She is (a) beautiful, fatient handphones rich and tall”

"she is (a) beautiful clever, kind and tall"

"she is (a) good looking king and clever"

Inappropriate article

"He name is colojoh" inappropriate pronoun

"is seven years old" no $\mathbf{S}$

"first old brother name is arfan" incomplete $\mathbf{S}$

"second old brother name is ma'tuis" incomplete $\mathbf{S}$

Those sentences above become a measurement indicating that the composition of student 12 is not free from grammar error category. Although the other categories of grammar rule which are used in this research are presented in no error.

Student 13 (ST13). The result of the analysis indicates that four of twelve categories are presented with some errors which effecting incomplete comprehension. Those errors occur in the use of singular/plural, article, preposition and subject omission. The first error is in the use of singular/plural noun, article, preposition, and subject omission. The errors of those four categories are found in some sentences below:

"I have four young brother" inappropriate singular/plural noun "she is (a) beautiful, kind, an patient" 
"she is a beautiful, clever......"

"...... studying ( ) class seven / one"

"...... studying ( ) class six / one"

"...... studying ( ) class / six one"

“...... studying ( ) class fore / one"

Neglecting preposition "at"

"Brother. ( ) is good-looking, kind......"

"Brother. ( ) is handsome, rich, thin....." "Brother. ( ) is beautiful, kind, tall....." $\}$ neglecting "subject"

"( ) studying class / six one"

"Brother. ( ) is clever, talk active, thin...."

"( ) studying class..."

Those all sentences mentioned above prove that student 13 does not apply all grammar rules on the composition accurately. Nevertheless, the other eight categories are presented with no errors.

Student 14 (ST14). Based on the analysis of standard grammar rule, the composition of student 14 is presented with some errors in the grammar categories. They occur in the use of singular/plural noun, article, verb omission and subject omission.

Here are some sentences which are presented with inaccurate grammar in the use of singular/plural noun. It occurs on the sentences "she has one children..... ", "my sister are married", "one children.....", "two old brother", "two old sister", and "my mother has five sister". Then, the error of the inappropriate articles happen in sentence "she is (a) beautiful, kind, and rich" and "my father is (a) engineer". There are two sentences which are presented with no subject, they are "( ) are in Narathiwat" and "( ) is 60 years old". Student 14 neglects subject in both of those two sentences. The last is "my third sister ( ) a teacher". This sentence is presented without verb.

\section{DISCUSSION}

In this session, the researcher presents a discussion based on the findings of the study in the previous session. Then, those findings are related to the theories in some sources. This discussion deals with the two research questions mentioned in chapter I. They are: (1) how is the grammatical accuracy of Thai students' English writing at Darawithaya School? and (2) how are the cohesion and coherence 
aspect of Thai students' English writing at Darawithaya School? Based on the findings of the grammatical accuracy, cohesion and coherence analysis, there are some errors that participants present in some categories of grammar rule which were used to measure the grammatical accuracy and a rating scale for cohesion and coherence aspect of participants' compositions in this research. These findings refer to two kinds of analysis: grammatical accuracy and the aspect of cohesion and coherence which were examined individually in each composition of 14 participants.

\section{Grammatical Accuracy}

In this aspect, the finding indicates some categories of grammar rules which are presented inaccurately and in a great measure is presented accurately. Those some categories which are frequently presented in errors are:

\section{The use of singular/plural noun}

Many sentences of students' writing are presented the use of singular/plural noun in inappropriate manner. Some students neglect $-\mathrm{s}$ in the final of word which indicates plural and present $-\mathrm{s}$ in singular nouns. Those are found in the some sentences below:

The examples of error singular/plural use on students' sentences.

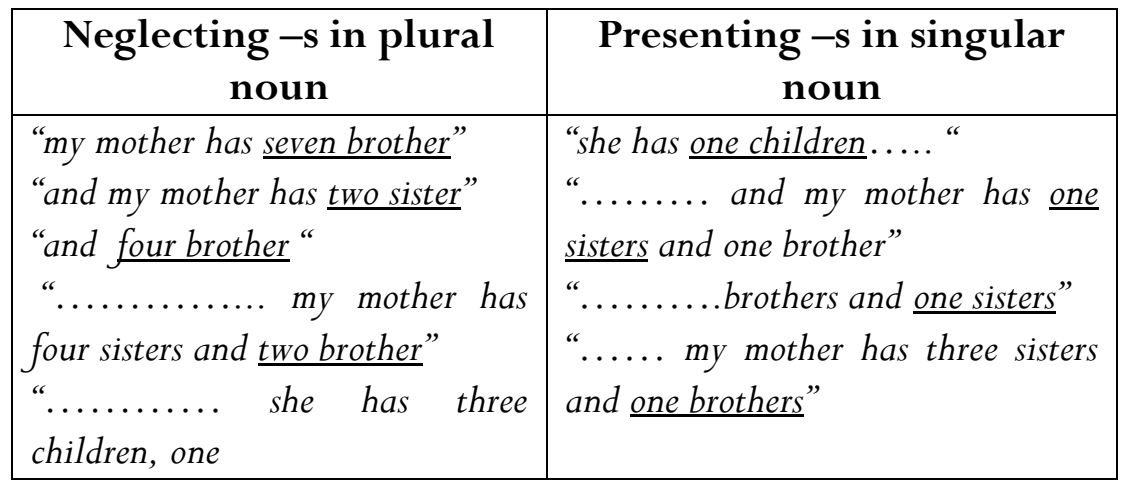

The nouns underlined in the left column correctly should be added $-\mathrm{s}$ in the final of each noun because they indicate the nouns into plural. Meanwhile, the nouns underlined in the right column correctly should remove $-\mathrm{s}$ in the final of each noun because they indicate the 
nouns into singular. This theory is based on the plural noun rules on the grammar book written by Irene E. Schoenberg and Jay Maurer (Irene: 2002). The other source of this singular/plural noun rule stated clearly by Marcel Danesi on his book "common nouns are subdivided into count and non-count. Count nouns refer to anything that can be counted (one book, two books and so son). They can be specified with any article, numeral, or quantity term (many, several) and have both singular and a plural form" (2002). The rules of those statements explain that plural noun (regular) should be added - s/es. Then, for the singular noun should not be added $-\mathrm{s} / \mathrm{es}$. This analysis is also based on the rules of singular and plural nouns created by Betty, she explains that a final $-\mathrm{s}$ or - es is added to a noun to make a noun plural (Betty: 1989).

* The noun "sister" in this sentence "my sister are single" is intended to explain the word "my sister" in plural type. It can be seen from the next sentences that explain about the first and second sister. Meanwhile, the use of to be "are" at that sentence is absolutely correct.

The error of this category may be because Thai and English differ in realizing the plural concept of nouns. While English makes distinction between singular and plural forms of a noun, Thai does not. The plural morpheme $-\mathrm{s}$ needs to be added to a noun in English to indicate the plural meaning. Thai, in contrast, employs numerical descriptions to indicate the plural meaning (Charuporn: 2001).

\section{The use of Articles}

The finding of this research also finds some errors in the use of article in some sentences which are presented on students' composition. The examples of error article use on students' sentences.

\begin{tabular}{|l|l|}
\hline Neglecting an article & Presenting an article \\
\hline "my fourth sister is student". & "He is a handsome, brave, clever, and \\
& kind" \\
& "she is a fat, beautiful, and kind". \\
& "Sister she is a beautiful, \\
& clever............. . \\
& "My father is a Engineer" \\
\hline
\end{tabular}


In the left column, the use of article $-a$ is neglected. Whereas, the article $-a$ is needed in that sentence to indicate the noun in singular. Then, for the use of article $-a$ in the right column is not necessary to be presented, because there are no antecedent provided on those sentences. For instance "He is $\underline{a}$ handsome. In this sentence, the article $-\mathrm{a}$ is appropriate to be presented. Hence, Omitting the article $a$ of those sentences above is the correct manner (Marcel: 2006). Betty argues on her grammar book that usually a/an is used with a singular generic count noun. For examples: $\underline{\mathbf{A}}$ window is made from glass, parent must give $\underline{\mathbf{a}}$ child, $\underline{\mathbf{A}}$ box has six sides.

Marcel Danise also gives clear information dealing with the rule of article usage in sentence (2006). He states that there are two distinct forms of the indefinite article: (1) $\boldsymbol{a}$ before a consonant or $\boldsymbol{u}$ pronounced as "yooh"; and (2) an before a vowel or "silent h" (h that is not pronounced):

\section{The use of pronoun}

Besides those error categories above, the use of pronoun also becomes one of the categories which is found on students' compositions. Those errors occurred on the sentence below:

\begin{tabular}{|l|l|l|}
\hline "My father is a teacher at Bon Sipo & "He name is colojoh" \\
School. She is good-looking, kind, fat...." & "he name is Rohimah", \\
"I love my mother she is a beautiful & \\
patient............... He name is Aruni" &
\end{tabular}

In the use of pronoun "she" in the sentence "My father is a teacher at Bon Sipo School. She is good-looking, kind, fat...." should be changed into "he" because it refers to a man, my father. In this case, my father is the antecedent of that sentence. (2006). Therefore, the appropriate pronoun should be "he" not "she".

Also the second sentence, "I love my mother she is a beautiful patient............ He name is Aruni", the use of pronoun "He" is inappropriate in this sentence. The use of pronoun "he" does not represent the previous subject that student intends to be explained. The appropriate pronoun of this sentence is "her". Because that refers to "my mother", singular third person that shows a girl/woman (2006). 
Marcella writes on her grammar that the person of being spoken of, called the third person. Singular -he (for male), -she (for female), -it (for thing; also for live beings whose sex is unknown or unimportant for the speaker). Plural -they (for all live beings and for all things). It means that the subject "my mother" indicates a woman, then, the pronoun "he" was intended to explain about the ownership of the name of my mother" itself .

This case also occurs on the sentence "he name is Rohimah. The use of pronoun "he" is inappropriate. It correctly uses "her". It refers to the word "sister" in the previous sentence. That rule is supported by the other source of possessive adjective grammar rule (Fuad: 2005). Fuad states that possessive adjective is a noun which shows ownership/possession, and it is followed by noun. In this case, the ownership of the name Rohimah is woman. Therefore, the appropriate pronoun is "her" not "he".

Pronouns are words used in place of nouns, substantives (words taking on the function of nouns), or noun phrase (noun accompanied by articles, demonstratives, adjectives, and so on). The noun that a pronoun replaces is called an antecedent (Marcel: 2006).

\section{Grammar rules of pronoun}

Antecedence

John is American

That book belongs to Marry

That woman is American

Give that book to John

\section{Pronoun}

He is American

That belongs to Marry

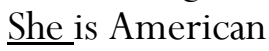

Give that book to him

\section{Subject and Verd Agreement}

The other error also happens in the use of S-V agreement rule. Some sentences are provided by participants with no appropriate subject and verb. That has been found on the sentence "My sister and single. My first sister is a student......... My second sister............" The use of "and" does not present the verb of that sentence. That sentence is nominal sentence by explaining some information of the subject " $m y$ sister". Therefore, it is correctly changed into to be "is". John S. Hartanto and friends state that "to be" is used to combine between subject and complement of the sentence. The complement of sentence 
can consists of adjective, noun, adverb, and verb showing continuous (e.g. John, Koentjoro, manaf: 2009) In the present tense, the use of "to be" are am, are, is depends on the subject. In this case, the appropriate "to be" is "is" because the subject of that sentence is singular third person. Therefore, it is correctly changed into "to be" "is" as the V-agreement of Subject "he". This case is same as the previous sentence. Then, the error also occurs on the sentence "My family live in balo" This sentence is neglected $-\mathrm{s}$ in the final of the word "live". It is appropriately added $-\mathrm{s}$ to agree with the subject "my family". John Langan states that a verb must agree with its subject in number. $A$ singular subject (one person or thing) takes a singular verb. A plural subject (more than one person or thing) takes a plural verb (2009).

\section{Word formation}

This error category occurs on the two sentences. They are:

"... and she has two

"......... and she has red-hair, and she is sister"

The first sentence is presented by neglecting word form "noun". After the word "two" in that sentence, ideally should be added a word form "noun" to make that sentence consists of complete object. Because the sentence "... and she has two__ " hangs without any complete object. Then, the use of the word "sister" in the second sentence was not appropriate. It does not offer any logical idea to present that sentence.

\section{Subject Omission}

There are two sentences found with no subject. Students write some compositions by neglecting subject of the sentences. In this study, it refers to the error in the use of subject omission category. The errors of this category are found in some sentences. For example: "is five years old" and "is good-looking thin and kind". The first sentence is presented without subject. It means that student omits subject that properly should be presented. Also, the second sentence is in the same case. As stated clearly by John, "every sentence has a subject and a verb. Who or what the sentence speaks about is called the subject; what the sentence says about the subject is called the verb" (2009). This statement means that every sentence should have subject 
and verb. The error of this category also occurs on some other sentences below:

"Brother. ( ) is good-looking, kind......" "Brother. ( ) is handsome, rich, thin.....", "Brother. ( ) is beautiful, kind, tall......", “ ( ) studying class I six one", "Brother. ( ) is clever, talk active, thin.....", " ( ) studying class...", "( ) are in Narathiwat" and " ( ) is 60 years old”.

Those all sentences above were presented with no subject.

\section{Verb Omission}

This category connects with the previous category, Subject Omission. If in the previous category discusses about the sentences which are presented with no subject, this category discusses about some sentences which are presented with no verb. As stated by John that every sentence should present subject and verb, "every sentence has a subject and a verb. Who or what the sentence speaks about is called the subject; what the sentence says about the subject is called the verb" (2009). Unfortunately, there are some sentences which are not presented with no verb. For instance, "his name ma'sadee" is presented with no Verb. Properly, "to be" -is should be added to make that sentence complete. This case also occurs in the sentence "my third sister ( ) a teacher" and "My fourth name barakat".

\section{Extraneous subject}

Extraneous subject is also found in students' composition. In sentence "Sister she is a beautiful, clever..........", the subject is provided in double, "sister" and "she". One of them is properly used one, not both. The other sentence is "sisther she is a good-looking, beautiful.....", and "....... and red hairs anahan she is 5 years old".

The use of subject does not seem to be a big problem for Thai students participating in this study. This is not surprising, however, due to the fact that both Thai and English are similar in structure of the sentence, subject-verb-object (S-V-O).

\section{Preposition}

Some sentences below are presented with no appropriate preposition.

“...... studying ( ) class seven / one”, “...... studying ( ) class six / one”, “...... studying ( ) class / six one”, and “..... studying ( ) class fore / one" 
Based on the rule of preposition, there are some types of preposition provided. One of them is preposition for position. There are three kinds of preposition which are used for position, they are in or inside, on and at (Marcell: 2006).

In or inside : giving the area of something enclosed - a container, a drawer, a room, building, world - . For example: "Hang your coat in the closet! "

On $\quad$ : indicating the surface of something - a floor, a wall, a desk, a street. For instance: "Put the dishes on the table!"

At : refers to a general vicinity. For instance: "He is at school"

Made reference to the rule by Marcella frank above, those sentences are lack of the use preposition "at" in each sentence. Hence, the idea of each sentence refers to the general location that the subject takes, a class of school. Based the finding of grammatical accuracy of all students, most students present the use of tense, and fragment in free from error. It means that students have good understanding in the way to use an appropriate tense in their writing. For the category of fragment, it does not guarantee they have understood well because of no error found. But, may be because the composition which is so simple, descriptive text about family.

\section{Cohesion and Coherence}

Viewed from the aspect of cohesion and coherence, the compositions of student 1 up to student 14 mostly present appropriate manners in connecting one sentence to another. It can be seen from the way of how students present those two aspects. As stated by Jeremy Harmer on his book, "for writing to be truly accessible, however, it also needs to be both cohesive and coherence" (Jeremy: 2004). This statement means that a writing will be truly acceptable for readers if it has both cohesion and coherence aspect on the text itself. Therefore, other than grammatical accuracy aspect this study also concerns on those two aspects in analyzing students' writing. The way of how students arrange the organization of the text and express the ideas is almost same. This case is influenced by students' learning method 
which used to using memorizing. Before students wrote the compositions for final work, they were taught the material, given the examples and then given some exercise to do that. So did the descriptive text material. With the result above, students dispose following the construction given.

\section{Cohesion}

All participants introduce all new information accurately, that is about family. For example: "I have a large family", "I have a family", and "I have little family". Then, in the second paragraph, most of them introduce new information by mentioning the member of their family and giving some description to support the information. For instance, "My grandfather, grandmother, father...." "my sisters are married" and "my sisters are single". Jeremy Harmer argues that the text is cohesive because there are lexical sets (that is words in the same topic area) which interrelate with each other (Jeremy: 2004). In this study, all students have had this cohesion aspect. All students present their composition by stating some lexical sets which agree with the topic, "My Family". In connecting this sentence with the next sentence, students continue by mentioning the members of their family and then describe more about them. Furthermore, the use of junction words is also presented correctly in some sentences which need those junction words. For example: "My father, my mother, young sister, and me", My mother has seven brother and sister", and "All my uncles and aunts live in Pattani, but my family lives in Narathiwat". All those junction words are correctly used in those sentences mentioned. One of the functions of Junction word "and" is used to combine the adjectives which are same in the purpose (Marcella: 1972). It means that the positive meaning with positive meaning, and the negative meaning with the negative meaning, for example "beautiful, tall, and kind", "good-looking, kind, fat, and clever". Also to combine noun and noun, as like at the sentences "My father, my mother, young sister, and me", and "My mother has seven brother and sister".

As stated by Supong Tangkiengsirisin that junction word is the type of cohesion that involves the use of relations performing the main function of connecting sentences. Conjunction or connective links two 
ideas or more ideas in a text or discourse together semantically. With the use of conjunction, the understanding of the first idea will give the interpretation of the second idea (Supong: 2010). Hence, regarding the importance of connecting the sentence with the other sentence in a text, the use of junction words on students' composition was analyzed carefully. Even the use of ellipsis is one of the aspects to measure the cohesion of the text, it is not applied in students' composition of this study. It is not because of this point unnecessary to be analyzed, but because the compositions that all students (participants) make are very simple and basic writing. Therefore, even the use of ellipsis becomes one of the categories that is used to measure the cohesion aspect of writings, it is not too being considered. Further, repeated vocabulary also presented where it is not necessary at that sentence. For example: "my first sister is a student. She is thin. She has long wavy hair, and she is rich". The pronoun "she" that are underlined do not need to be repeated because those sentences explain about the characteristic or adjectives of her first sister, same as in the previous sentence "she is thin". Hence, those pronoun underlined are better omitted and directly combined those three sentences by adding coma (,) and "and". With the result that, that sentences become "My first sister is a student. She is thin, long wavy hair and rich". In cohesion device, repeating the words which have been stated before, can be done by "reference". Halliday and Hasan define "reference" as "the relation between a component of the text and something else by reference to which it is interpreted in the given instance." (Supong: 2010). Here, reference can be categorized into three subtypes. One of them is personal reference is achieved through the use of personal and possessive pronouns, and possessive adjectives.

There are also some sentences that ideally are presented with some junction words to connect one word to another words are provided with no junctions. For example: "there are grandmother, grandfather, father, mother". If there are some nouns which become a complement in a sentence, punctuation "and" should be presented before the last noun to indicate that it is as the last noun of that sentence (Marcella: 1972). That sentence properly is "there are grandmother, grandfather, father, (and) mother". This case also happens on the sentence "he is handsome, kind, clever, rich". The complement of this 
sentence consists of four adjectives with no junction words. Therefore, the use of "and" is needed to be presented before the last adjective. Then, the last aspect of cohesion which is presented unsatisfying is the examples of each idea presented. Most of the ideas are let without any more information. For instance, student explains that his father is rich, handsome, tall, and kind. In this case student does not give any example to support how rich, how handsome, how tall, and kind her father is.

\section{Coherence}

Regarding cohesion and coherence are closely related, Connor and Johns give a distinction. Both cohesion and coherence provide connectivity in a text or a discourse and facilitate understanding. The distinction, cohesion refers to the syntactic and semantic connectivity of linguistic forms at a surface-structure level. Meanwhile, coherence concerns to the overall connectedness of the ideas in a piece of writing rather than (inter)relationships between sentences (Supong: 2010). The larger scope of coherence includes discourse-level relations and is "the internal set of consistent relationships perceived in any stretch of discourse". (2010). Those two statements give clear information dealing with the difference area of those cohesion and coherence aspect in assessing a composition of writing.

Analyzing coherence aspect of students' composition participating in this study is considered important. As Jeremy harmer said that when a text is coherent, the reader can understand at least two things: writer's purpose and writer' line of thought (Jeremy: 2004). Therefore, those 14 compositions of students participating in this study were analyzed carefully in this aspect. The finding of coherence aspect analysis in compositions made by students shows satisfying presentation for the readers. The subject is introduced effectively in the beginning section, all of the ideas are relevant to the topic and well-related to one another, points of view of the writer are presented clearly, and the conclusion is given powerfully. Jeremy Harmer states, "For a text to have coherence, it needs to have some kind of internal logic which the reader can follow with or without the use of prominent cohesive devices" (2004). Regarding the finding of this study, most 
students' composition has presented the logic ideas relating to the topic sentence mentioned.

To make sure, here are the example of some students' writing: "I have small family" is the topic sentence, "My family has four people" is giving new information dealing with the family, "My father, my old sister, and $m e$ " this sentence is connected with the previous sentence, mentioning about those four people, and "I have a large family", this sentence is the topic sentence provided in mostly all the composition of students. It is regarded as appropriate sentence to begin the paragraph at students' writing considering the ideas of the whole sentences discuss about family. Giving clear point of view in some sentences are shown by ideas asserting their father and mother's old, the profession and the characteristics of their parent clearly and many other information provided. For example: "my father is 45 years old, and my mother is 44 years old. My father is a teacher at Ban Sipu School. She is good-looking kind, and clever". Further, students also explain about their sisters and brothers; the profession, the old, and the characteristic of each of them. It can be seen from the sentences " $m y$ first sister is a student. She is tall, friendly, good-looking. She is 17 years old. My second sister is a student. She is beautiful, tall, and kind". And most of them conclude their composition by presenting the sentence "I love my family". It is valued as a clear conclusion representing all of ideas of the whole paragraph which relevant with the topic sentence. Yet, there are few students which present unclear ideas on their writing. For instance: in the beginning of the paragraph student 10 introduce ideas that her family consists of five people, "My family has five people". But she continues the next sentence by explaining six people in her family, "My father, mother, two young sister, one young brothers, and me". Those two sentences reveal that the ideas are not related one to another. Then, in the whole of the writing only describes physically about her mother and father. She does not describe about her sister and brother however in the first ideas she mentions them. Those findings give information that student 10 does not present points of view of the writer clearly.

The other example occurs on student 4 composition. There are some ideas which are not well-related with other ideas of that composition, event those ideas are relevant to the topic. For example: 
student 4 explains that her family has three people, "my family has three people" then she continued with the next sentence "my father, my mother, one young brother, two old brothers, and me". Those two sentences are not well-related to one another. In the first sentence explains six people in the family but the explanation on the next sentence describes six people. Lastly, most of students present clear conclusion in the end of their composition. For instance: "I love my family", "I love my family very much", and I love my father and mother". Those all ideas represent the whole ideas of the description of the family in the whole text. Jeremy Harmer argues that a conclusion of writing, writer ends the paragraph by reminding the readers or evaluating about the opening topic sentence (2004). In this study, most students end their composition by retelling the topic sentence.

\section{CONCLUSION}

The main result of this research is focused on the grammatical accuracy on students' composition, cohesion and coherence aspect. The conclusion of this result will be determined as follow:

\section{Grammatical Accuracy}

The study presents a descriptive analysis of compositions written by Thai EFL students at second grade of Senior High School at Darawithaya. Based on all students' composition, can be concluded that from 14 students' compositions, there are 73 grammar uses which are presented inaccurately. From 12 categories of grammar accuracy measurement which are used in this research, found the errors in each all category, except the use of fragment and verb formation. Those 12 categories include singular/plural, pronoun, tense, article, preposition, word formation, verb formation, verb omission, subject omission, extraneous subject, S-V agreement, and fragment.

The grammatical accuracy of students' compositions in this study is varied from one student to other students. There are five classifications which are decided based on the assessment rubric for the writing task; very good, good, fair, weak and failed. There are four students of fourteen students whose the grammatical accuracy is very good. This category is valuated as composition which consists of occasional mistakes of grammar use which do not impede 
understanding of the text. Then, seven students are classified into good grammatical accuracy. There are some mistakes of grammar use which rarely impede understanding found on their writings. Beside that, there is only one composition which is categorized into fair. In this composition, some mistakes of grammar use which rarely impede understanding established. Lastly, weak category of grammatical accuracy occurs on two compositions. Those compositions have numerous mistakes which may cause struggle for the reader and slightly compromise task development. And none of composition is classified into failed.

\section{Cohesion and Coherence}

Viewed from coherence and cohesion aspect, students' compositions present well organization in connecting the sentences and express the ideas to relate one another. Most students begin their writing by introducing clear and relevant subject by stating the sentence "I have a large family", "I have a family", and "I have little family", Then, students present some ideas in the composition which are relevant to the topic and relate the ideas to one another. Each student composition describes about family. Furthermore, students end the composition by stating clear and simple conclusion, "I love my family", I love my family very much", "I love mother and father very much. There are two students who do not present a conclusion, they are student 9 and student 13.

Regarding the cohesion analysis of all students' composition, there are some sentences which are not separated well with other sentences. Then, no punctuation applied appropriately in some sentences/ideas to separate one idea to other ideas and to separate one sentence to other sentences. Same as the evaluation of grammatical accuracy on the assessment rubric for the writing task, there are five categories in determining students' composition based on the aspects of cohesion and coherence, they are very good, good, fair, weak and failed. Three compositions are determined as the students who present very good in cohesion and coherence aspect. The consideration of this category is; presenting very well-organized and internally coherent, showing a very clear progression of information or ideas, expressing varied and successful use of cohesive devices. Then, the compositions 
of eleven students are classified into writings which consist of good cohesion and coherence aspect. Mostly the sentences are organized and the ideas are clear and coherent. Then, satisfactory use of cohesive devices which may not consistently maintained. From 14 students' compositions, none of them are determined as fair, weak and failed categories.

\section{REFERENCES}

Ary, D., Cheser, L., Jacobs, \& Christine, K. S. 2010. Introduction to Research in Education Eighth Edition. Wadsworth: Canada.

Ayuwaratana, N. 2002. An Error of Analysis of Fourth Year English Majors' Research Proposal. Master of Arts an Independent Study Report in English, Khon Kaen University.

Azar, B. S. Understanding and Using English Grammar: Second Edition. The United States of America, 1989.

Baleghizadeh, S. \& Gordani, Y. 2012. Academic Writing and Grammatical Accuracy: The Role of Corrective Feedback.

Bennui, P. 2008. A Study of L1 Interference in the Writing of Thai EFL Students. Malaysian Journal Of ELT Research, Vol. 4, pp.74. Retrieved from www.melta.org.

Bootchuy, T. 2008. An analysis of Errors in Academic English Writing by A Group of First- Year Thai Graduates Majoring in English. Graduate School, Kasetsart University.

Brown, H. D. 2007. Teaching by principles: an interactive approach to language pedagogy, Third Edition. United States of America: Pearson Education.

Chastian, K. 1990. Characteristics of Graded and Ungraded Compositions. Modern Language Journal, 11,367-383.

Chiang, S. Y. 1999. Assessing Grammatical and Textual Features in L2 Writing Samples: The Case of French as A Foreign Language. Modern Language Journal, 83,219-232

Chownahe, P. 2000. An Error Analysis of English Compositions Written by Mattayomsuksa Six Students. Master of Arts Thesis in English, Khon Khaen University. 
Creswell, J. W. 2012. Educational research: planning, conducting, and evaluating quantitative and qualitative research / John W. Creswell. - 4th ed.

Danesi, M. 2006. Basic American Grammar and Usage: an ESL/EFL Handbook. The United States of America.

Frank, M. 1972. Modern English: A Practical Reference Guide. The United States of America.

Frantzen, D. 1995. The Effects of Grammar Supplementation on Written Accuracy in an Intermediate Spanish Content Course. Modern Language Journal, 79, 329-344

Harmer, J. 2004. How to Teach Writing. England.

Hartanto, J. S., Koentjoro, S., Seputro, M. A. 2009. Accurate, Brief and Clear: English Grammar. Surabaya.

Interviewed a teacher of Darawithaya School. Taken on March 19th, 2015.

John M. S. \& Christine B. F. 1994. Academic Writing for Graduate Students: Essential Tasks and Skills (The University of Michigan Press).

Kitjaroonchai, N. 2013. Motivation Toward English Language Learning of Students in Secondary and High Schools in Education Service Area Office 4, Saraburi Province, Thailand. International Journal of Language and Linguistics. 1(1), 22-33. doi: $10.11648 /$ j.ijll.20130101.14

Kobayashi, H., \& Rinnert, C. 1992. Effects of First Language on Second Language Writing: Translation Versus Direct Comparison. Language Learning, 42, 183-215.

Kroll, B. 1990. What Does Time Buy? ESL Student Performance at Home Versus ClassCompositions. In B. Kroll (Ed.), Second Language Writing: Research Insights for the Classroom (pp. 140-154). Cambridge: Cambridge University Press.

Mas'ud, F. 2005. Essentials of English Grammar: A Practical Guide Edisi 3. Yogyakarta.

Merriam, S. B. \& Associates. 2002. Qualitative Research in Practice: Examples for Discussion and Analysis. San Francisco: JosseyBass A Wiley Company. 
Polio, C. G. 1997. Measures of Linguistic Accuracy in Second Language Writing Research. Language Learning, 47, 101-143

Shahid Beheshti University, G.C. Irán. Gist Education and Learning Research Journal. ISSN 1692-5777.

Schoenberg, I. E., Maurer, J. 2002. Focus on Grammar: An Introductory Course for Reference and Practice. The United States of America.

Shahriar, A. - Pathan, H. 2012. "Coherence and the Role of Cohesion in Coherent Texts". Language in India www.languageinindia.com, Vol.12.

Tangkiengsirisin, S. 2010. "Promoting Cohesion in EFL Expository Writing: A Study of Graduate Students in Thailand". International Journal of Art and Sciences. 3 (16).

Tiptida, B. 2008. An Analysis of Errors in Academic English Writing by A Group of First- Year Thai Graduates Majoring in English. Graduate School, Kasetsart University.

Walter, E., Cranz, D., \& Glannon D. 2008. Cambridge Dictionary Learners' Dictionary. Cambridge University Press.

Watcharapunyawong, S., \& Usaha, S. 2012. Thai EFL Students' Writing Errors in Different Text Types: The Interference of the First Language. English Language Teaching; 6 (1), 67. doi:10.5539/elt.v6n1p67. 